OPEN ACCESS

Edited by:

Laura Elvira Prino,

University of Turin, Italy

Reviewed by:

Paola Magnano,

Kore University of Enna, Italy Mario Filippo Paolo Bellomo,

Kore University of Enna, Italy

*Correspondence:

Nan Zhou

nanzhouchina@gmail.com

Xiaoyi Fang

fangxy@bnu.edu.cn

Specialty section:

This article was submitted to

Educational Psychology,

a section of the journa

Frontiers in Psychology

Received: 16 November 2018 Accepted: 05 February 2019

Published: 21 February 2019

Citation:

Zhang YC, Zhou N, Cao H, Liang Y, Yu S, Li J, Deng L, Sun R, Wu Q, Li P, Xiong Q, Nie R and

Fang $X$ (2019) Career-Specific

Parenting Practices and Career

Decision-Making Self-Efficacy Among

Chinese Adolescents: The Interactive

Effects of Parenting Practices

and the Mediating Role of Autonomy.

Front. Psychol. 10:363

doi: 10.3389/fpsyg.2019.00363

\title{
Career-Specific Parenting Practices and Career Decision-Making Self-Efficacy Among Chinese Adolescents: The Interactive Effects of Parenting Practices and the Mediating Role of Autonomy
}

\begin{abstract}
Yu Chi Zhang ${ }^{1}$, Nan Zhou ${ }^{2 *}$, Hongjian $\mathrm{Cao}^{2}$, Yue Liang ${ }^{3}$, Shulin Yü, Jian $\mathrm{Li}^{2}$, Linyuan Deng', Ruixi Sun ${ }^{2}$, Qinglu Wu ${ }^{5}$, Ping Li ${ }^{1}$, Qing Xiong ${ }^{1}$, Ruihong Nie ${ }^{1}$ and Xiaoyi Fang ${ }^{1 *}$
\end{abstract}

\begin{abstract}
1 Institute of Developmental Psychology, Beijing Normal University, Beijing, China, ${ }^{2}$ Faculty of Education, Beijing Normal University, Beijing, China, ${ }^{3}$ Department of Psychology, School of Education, Guangzhou University, Guangzhou, China, ${ }^{4}$ Faculty of Education, University of Macau, Macau, China, ${ }^{5}$ Department of Social Work, The Chinese University of Hong Kong, Shatin, China
\end{abstract}

This study examined the unique and interactive effects of various career-specific parenting practices (i.e., parental career support, interference, and lack of engagement) on Chinese high school students' career decision-making self-efficacy (CDSE) as well as the mediating role of autonomy in such associations. Based on data from 641 Chinese high school students $(47.6 \%$ male; mean age $=15.28$ years old, $S D=0.49)$ in 2016, two moderated mediating effects were identified. Higher level of parental career engagement strengthened the positive association between parental career support and adolescents' autonomy, which in turn, was associated positively with adolescents' CDSE. Parental career interference related negatively with adolescents' CDSE via autonomy when lack of parental career engagement was low, but related positively with adolescents' CDSE via autonomy when lack of parental career engagement was high. These findings advance our understanding of the underlying processes between career-specific parenting practices and adolescents' CDSE. Implications for practices were discussed.

\footnotetext{
Keywords: career decision-making self-efficacy, career-specific parenting practices, Chinese adolescents, autonomy, high school
}

\section{INTRODUCTION}

Career decision-making self-efficacy (CDSE), which refers to one's confidence in one's ability to engage in educational and occupational planning and decision making, is a critical indicator of adolescent career competence (Luzzo, 1993; Chiesa et al., 2016). CDSE typically serves as an important trigger to promote career outcomes, including career decision-making skills (Luzzo, 1993; Choi et al., 2012), career planning outcome expectations (Gushue, 2006), stable career 
identity (Cordeiro et al., 2015), and lower career indecision (Guay et al., 2003). CDSE is especially critical during high school years when adolescents are supposed to make important career-related decisions. Students who are highly confident about their capacity in making better career decisions would have more interest to nurture their career goals, devote more time to their career explorations, and may probably make better career decisions ultimately (Gushue et al., 2006; Chiesa et al., 2016). Thus, it seems warranted to identify the antecedents of adolescents' CDSE (Miles and Naidoo, 2017).

Research reveals that parenting practices have been implicated in the development of adolescents' CDSE (Gushue and Whitson, 2006; Sovet and Metz, 2014). However, previous research is limited in several ways. First, most of the research on parenting and CDSE focuses on the effects of general parenting practices (e.g., parental support) with few studies examining associations between career-specific parental practices in relation to adolescents' CDSE (Garcia et al., 2012). In fact, careerspecific parental practices may yield stronger relations with adolescents' career development than general parenting practices (Tracey et al., 2006). Second, the slim body of research that examined career-specific parenting practices and CDSE typically examined a given type of career-specific parental practices (e.g., parental career support) (Keller and Whiston, 2008). Different career-specific parental practices, however, may have unique or interactive effects on career development (Guan et al., 2015). Thus, it is unclear which type of careerspecific parental practices would play a more vital role in shaping adolescents' CDSE, and whether different career-specific parental practices cooperate with each other in relation to adolescents' CDSE.

Furthermore, the underlying mechanisms linking careerspecific parenting practices to adolescents CDSE are not well understood. Self-determination theory (SDT) appears to provide a conceptual framework to explaining this underlying process (Deci and Ryan, 1985, 2000). SDT suggests that individual's development is promoted and sustained by individual-context interaction process. As one of the three important psychological needs, autonomy may serve as the origin and motivating agent of adolescents' development. Social contextual factors (e.g., parental practices) could promote or hinder adolescents' developmental outcomes through facilitating or forestalling the development of autonomy. Thus, autonomy may serve as a linking mechanism in the associations between career-specific parenting practices and CDSE. Taken collectively, the goal of this study is to examine the direct and interactive effects of test career-specific parenting practices on Chinese high school students' CDSE as well as the mediating role of autonomy in such associations.

\section{Career-Specific Parenting Practices and Adolescents' CDSE}

Bandura (2002) proposed that self-efficacy was domain-specific and CDSE is the key indicator of self-efficacy in the face of career decision (Choi et al., 2012). Social cognitive career theory (SCCT) posits that parenting practices could engender and increase individuals' career self-efficacy via several key self-efficacy learning experiences, including performance accomplishments, vicarious learning, social persuasion, and emotional arousal (Taylor and Betz, 1983; Lent et al., 1994). During the transition to adulthood, adolescents encounter many new options and uncertainties, and thus parental career support could be critical sources of guidance whereas parents' non-participative, neglectful or intrusive parenting practices may hinder adolescents' career planning, explorations, and the development of stable ego identity (Mortimer et al., 2002; Lim and Loo, 2003; Pellerone et al., 2017a,b). Specifically, parental career support (e.g., expressions of interests and concerns, encouragement, instrumental assistance, and emotional backing) could provide adolescents with positive career feedback (i.e., social persuasions) and thus may promote adolescents' confidence to embrace career challenges and to make career decisions (Zhao et al., 2012; Guan et al., 2016). In contrast, both parent career interference (i.e., parents' imposing their personal ideas on children's career directions and choices) or lack of parental career engagement (i.e., parents' inability or reluctance to get involved in their children's career development) may convey to adolescents that he or she is not competent and not capable to make career decision (Lim and Loo, 2003). In support of the hypotheses, Zhao et al. (2012) sampled 196 Singaporean university students and found that parental career support was related positively to youth's career self-efficacy and the lack of parental career engagement was related negatively to career self-efficacy.

In addition to the main associations between career-specific parenting practices and adolescents' CDSE, these parenting practices may also be configured in different patterns within individuals such that parental career support, interference, and lack of engagement may interplay with each other in shaping adolescents' career developmental outcomes (Dietrich and Kracke, 2009; Guan et al., 2015). Dietrich and Kracke (2009) found in a sample of 359 German adolescents that adolescents' perceived parental career support interacted with either career interference or lack of engagement in the prediction of adolescents' career decision-making difficulties. Specifically, the positive association between parental career support and adolescents' career exploration was stronger for adolescents who perceived higher parental career interference or those who perceived higher levels of parental lack of engagement. Guan et al. (2015) analyzed data from 244 Chinese undergraduates and their parents and found a similar interaction pattern involving parental career support and lack of engagement in the prediction of students' career exploration. Moreover, they also found that the negative effects of interference on career exploration were stronger among students with lower level of lack of parental career engagement.

Overall, the current literature on career-specific parenting are limited in several ways. First, most of the empirical studies on parenting practices and career development almost exclusively focused on general parenting practices or just parental career support (Lim and Loo, 2003; Tracey et al., 2006; Keller and Whiston, 2008; Garcia et al., 2012; Guan et al., 2016; Pedro et al., 2016). Thus, little is known about the differential associations between various aspects of career-specific parenting practices (i.e., parental career support, interference, and lack 
of engagement uniquely) and adolescents' career developmental outcomes, not to mention CDSE. Second, the interactions among career-specific parenting in relation to CDSE is not clear yet. To address these gaps, the first aim of this study was to examine the differential (i.e., unique) and the interactive effects of various career-specific parenting practices on adolescents' CDSE.

\section{The Mediating Role of Autonomy}

Most of the research focused on the direct associations between parenting practices and adolescents' career development. Thus, little is known about the underlying mechanisms that may explain such associations (Guay et al., 2003; Pesch et al., 2016). From a SDT perspective, autonomy may be a highly potential mediator (Deci and Ryan, 1985, 2000). Autonomy refers to the need to feel self-volition (Grolnick et al., 1991; Deci and Ryan, 2000). As one of three critical psychological needs, autonomy is considered as a crucial developmental task during adolescence and the developmental process may be impelled by continuous interactions between autonomy and dispositional integrative and social environmental influences (e.g., parenting practices; Deci and Ryan, 2000; Friedman et al., 2009).

First, parental support behaviors may facilitate adolescents' autonomy via encouragement of career planning and providing suggestions and directions for career explorations whereas both parental interference and lack of engagement may limit adolescents' opportunities to actualize self-governed career explorations and thus impede the development of autonomy. Second, autonomy may play a substantial role in promoting adolescents' CDSE via motivating adolescents to establish their career goals and to explore career interests (Deci and Ryan, 1985; Grolnick et al., 1991; Guay et al., 2003; Friedman et al., 2009; Zhou et al., 2009; Doren and Kang, 2016). Thus, career-specific parenting practices may be closely related to the need fulfillment of adolescents' autonomy in their career planning, explorations, and actions, which ultimately may lead to enhanced CDSE.

Several seminal work has supported the associations between career-specific parenting practices and adolescents' autonomy. Dietrich and Salmela-Aro (2013) conducted a longitudinal study on 807 Finnish adolescents and found that parents' career support was associated positively with, and lack of parental uniquely related negatively to adolescents' autonomous motivation 3 years later. Moreover, Costa et al. (2016) found that highly controlled parenting behaviors disrupted the adolescents' autonomy and led to heightened depression. This finding provide evidence that parental career interference would hinder the development of autonomy by limiting adolescent's opportunity to engage in self-governed career explorations and established their own career goals. Although the SDT and empirical studies have highlighted the importance of autonomy in shaping adolescents' developmental outcomes (Deci and Ryan, 2000; Pesch et al., 2016), to our knowledge, only one study explicitly examined the relation between autonomy and CDSE (Guay et al., 2003). Guay et al. (2003) sampled 834 college students and found a positive association between career decision autonomy and CDSE. This finding suggests that adolescents with higher autonomy may possess higher intrinsic motivation to set up career goals, to explore career interests and practice problem solving skills, which inevitably would facilitate their CDSE.

\section{The Cultural Context}

Previous research on relations between parenting practices and adolescents' CDSE has been primarily conducted in the Western culture (Keller and Whiston, 2008) and thus investigations in the Chinese context may be important because of the following considerations. First, the unique socioecological niches in which adolescents inhabit affect the importance of parenting practices in their children's career development. Although Chinese adolescents still need to navigate through the critical transition after completion of high school, the heightened pressure from Chinese college entrance examination prevent them from devoting sufficient time into establishment of career goals, making career plans, exploring career options (Fleisher, 2014). Without official national curriculum or programs to guide high school students' career development in China, Chinese parents' career-specific parenting behaviors are supposed to be of more importance to their adolescent children's career development as compared to their Western counterparts.

Second, in the more collectivistic cultural context (e.g., China), adolescents are supposed to consider significant others' opinions and family obligations when making career decisions (Pan et al., 2013; Sovet and Metz, 2014). Moreover, consistent with the traditional cultural filial piety, adolescents are instructed to endorse parental power and control rather than autonomy (Chirkov, 2009; Pan et al., 2013). Nonetheless, fulfillment of autonomy is a cross-cultural universal psychological need (Deci and Ryan, 1985; Zhou et al., 2009) and thus it is not clear autonomy could serve as a linking mechanism in the association between career-specific parenting practices and Chinese adolescents' CDSE. Taken together, examinations of associations among career-specific parenting practices, autonomy, and Chinese adolescents' CDSE may provide nuanced understanding of the importance of career-specific parenting practices in adolescents' career development and the applicability of SDT in the non-western culture, and also may provide important implications for Chinese adolescents' career guidance practices (Chirkov, 2009; Pan et al., 2013).

\section{The Present Study}

Based on data from 641 Chinese high school students, the present study examined: (1) the unique associations between three career-specific parenting practices (i.e., parental career support, interference, and lack of engagement) and Chinese high school students' CDSE; (b) the interactive effects of the three career-specific parenting practices on Chinese high school students' CDSE; and (c) the mediating role of autonomy in the associations between direct and interactive effects of the three career-specific parenting practices on Chinese high school students' CDSE. Child gender and parents' educational levels were specified as controls given their potential associations with parental career parenting practices and adolescents' CDSE (Gianakos, 2001; Guay et al., 2003; Patel et al., 2008; Choi et al., 2012; Hsieh and Huang, 2014). 


\section{MATERIALS AND METHODS}

\section{Participants and Procedures}

This study was meant to examine family processes and adolescents' career development. Participants were recruited through contacts with a public school in Beijing, China. Informed consent forms were taken home by students and completed by both parents and adolescents. All the parents permitted adolescents and all the adolescents themselves agreed to participate in the study, resulting in a sample of 646 participants. Five participants (three females and two males) were excluded because they did not complete the full questionnaires. The final sample comprised 641 (52.4\% female) 10th graders (response rate $=99.40 \%$ ) (Figure 1). Students' age ranged from 14 to 16 years old $(M=15.28, S D=0.49)$. Students' expected highest educational achievement ranged from junior college education to doctoral degrees with $47.90 \%$ of them anticipating a doctoral degree in future. Students' family socioeconomic status (SES) in the present study was indicated by parents' highest education level. Specifically, $82.7 \%$ of students' fathers and $74 \%$ of their mothers had at least college education.

The participating students completed the questionnaires in their classrooms. A research assistant explained to students about the purpose of the study. Students were informed that the information collected was totally anonymous and would only be used for research. The survey lasted for about $30 \mathrm{~min}$. Every participant get a gift (about \$1) after they completed the questionnaires. The project was approved by the university's institutional review board (IRB).

\section{Measures}

\section{Career-Specific Parenting Practices}

Career-specific parenting practices were assessed using the 15-item career-specific parental behaviors scale (Dietrich and Kracke, 2009). Participants rated the items on a 5-point Likert scale ranging from 1 (does not apply at all) to 5 (applies perfectly).

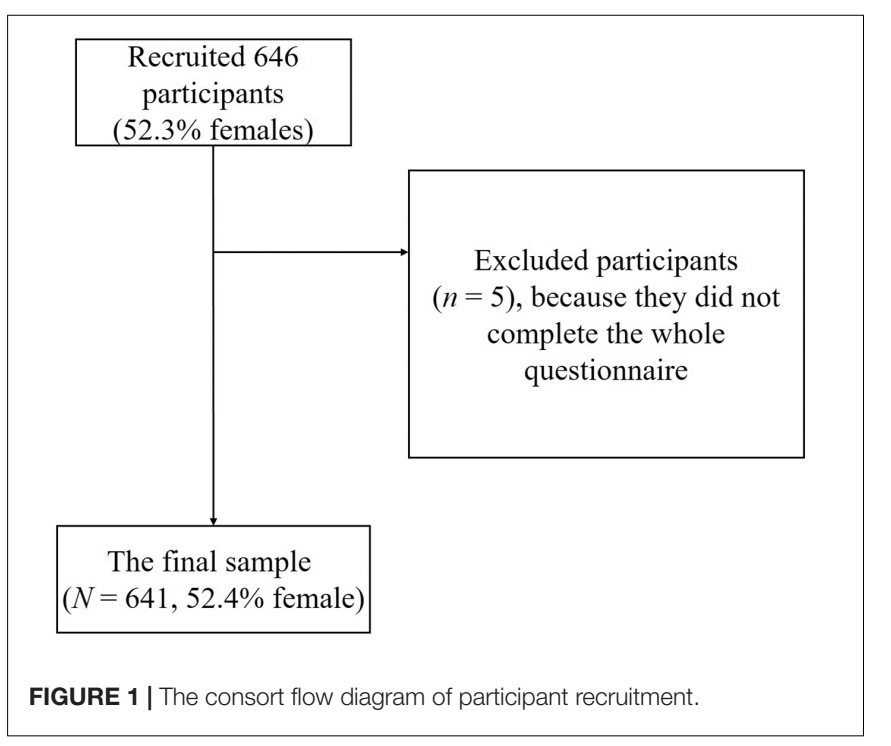

This scale contains three subscales: parental career support (e.g., " $M y$ parents encourage me to seek information about vocations I am interested in."), career interference (e.g., "My parents would talk me out of a vocation they don't like."), and lack of career engagement (e.g., "My parents don't care about my vocational preparation."). Mean scores were computed and used in the analyses and higher scores indicate that participants perceived their parents were more likely to employ particular behaviors. Previous studies have demonstrated that the PCB has good reliability and validity in Chinese samples (e.g., Guan et al., 2015). In the present study, Cronbach's alphas were 0.90 for parent career support, 0.88 for parent career interference, and 89 for lack of parent career engagement.

\section{Autonomy}

Autonomy was assessed using the 20-item Worthington Autonomy Scale (WAS) (Anderson et al., 1994). This scale includes two subscales: the behavioral autonomy (e.g., "I apologize for my part of an argument even if the other person doesn't.") and the emotional autonomy (e.g., "I can be close to someone and give them space at the same time.") subscales (Hmel and Pincus, 2002). Each subscale consists of 10 items. Participants responded on a 4-point scale ranging from $1=$ strongly disagree to $4=$ strongly agree. Mean scores were computed and used in the analyses and higher scores indicate greater autonomy. It has demonstrated good validity and reliability in Chinese samples (Zhou et al., 2009). In the present study, Cronbach's alphas were 0.72 for behavioral autonomy and 0.74 for emotional autonomy.

\section{Career Decision-Making Self-Efficacy (CDSE)}

Career decision-making self-efficacy were measured using the 25-item Career Decision-Making Self-efficacy Scale-Short Form (CDMSE-SF) (Betz et al., 1996). The scale asked participants to indicate their agreement with statements on a 5-point Likert scale ranging from $1=$ no confidence at all to $5=$ complete confidence (e.g., "I am able to make a plan of my goals for the next 5 years."). Mean scores were calculated and used in analyses and higher scores represent higher CDSE. Previous studies based on Chinese samples have demonstrated good reliability and validity of CDSE (Hampton, 2006; Garcia et al., 2015). Cronbach's alpha was 0.94 in the present study.

\section{Covariates}

Students reported their gender $(1=$ female, $0=$ male $)$ and their fathers' and mothers' educational levels $(1=$ primary school or less, $2=$ junior high school, $3=$ senior high school, $4=$ vocational school, $5=$ college education, $6=$ master education, $7=$ doctoral education).

\section{Data Analysis}

Hypotheses were tested using Structural Equation Modeling in Mplus 7.4, and missing values were handled using full information maximum likelihood estimation method (FIML; Acock, 2005). Parameters were estimated using maximum likelihood estimation. Although a non-significant chi-square statistic indicates a good model fit, a significant chi-square was expected for most models because of the large sample size. 
Therefore, other fit indices also were examined. Good model fit was indicated by the comparative fit index (CFI) values greater than 0.95 , the root mean square error of approximation (RMSEA) values less than 0.05 , and the standardized root mean square residual (SRMR) values less than 0.05 (Browne and Cudeck, 1993; $\mathrm{Hu}$ and Bentler, 1999; Byrne, 2001).

To test the direct and interactive effects of various careerspecific parenting practices on adolescents' CDSE and the mediating role of autonomy, we specified a moderatedmediation model (Figure 2). Specifically, parental career support, interference, and lack of engagement as well as the three-way and two-way interactions among and between these three parenting practices were specified as exogenous variables; autonomy was included as the mediating variable; and adolescents' CDSE was specified as the endogenous variable. Youth gender and parental education were included as control variables. The three career-specific parenting practices were correlated to account for their relatedness. Indirect effects were evaluated using bootstrapping, a non-parametric, resampling strategy to calculate indirect effects with no assumption about the shape of sampling distribution of the coefficients (Preacher et al., 2007). Specifically, for a given 95\% bootstrapped confidence interval, if zero is not included in the confidence intervals, the mediating effects are different from zero with 95\% confidence (Hayes, 2009).

\section{RESULTS}

Descriptive statistics and correlations for the key study variables are presented in Table 1. Correlations among parental career support, interference, lack of engagement, emotional autonomy, behavioral autonomy, and adolescents' CDSE were significant and in the expected directions. Given that all the data were collected at the same time using adolescents' self-reports, we used Harmon's one-factor test to examine potential common method bias (Podsakoff and Organ, 1986). We performed an exploratory factor analysis of all the items in this study. The first unrotated factor accounted for $38 \%$ of the total variance (less than 50\%), indicating that the common method variance in the present study was minimum (Podsakoff and Organ, 1986).

Prior to examining the whole model, the measurement model including all the exogenous, the mediator, and endogenous variables were included in a single model and correlated with each other. The factor loadings for the latent variable of autonomy were all significant at $p<0.001$ (the loadings were 0.79 and 0.86 for emotional autonomy and behavioral autonomy, respectively) and the model fit the data well: $\chi^{2}(7)=4.26, p=0.75$, CFI $=1.00$, RMSEA $=0.00(90 \%$ CI $[0.00,0.03])$, SRMR $=0.005$, indicating an adequate measurement model.

The integrative model that examined associations among three career-related parenting practices, autonomy, and CDSE, fit the data well (Figure 2): $\chi^{2}(22)=26.91, p=0.21$, CFI $=0.99$, RMSEA $=0.02$ with $90 \%$ CI $[0.00,0.04]$, SRMR $=0.021$. The three-way interaction among parental career support, interference, and lack of engagement was not related to adolescents' CDSE or autonomy. Two significant twoway interactions emerged. Parental career support interacted with parental lack of engagement when predicting adolescents' autonomy $(\beta=-0.22, p=0.003$; Figure 3$)$. Specifically, the positive association between parental career support and adolescents' autonomy was stronger among adolescents who reported low levels of parental lack of career engagement $(-1$ $S D, \beta=0.24, p<0.001)$ than those who reported high levels of parental lack of career engagement $(+1 S D, \beta=0.14, p<0.001)$.

Moreover, parental career interference interacted with lack of parental career engagement in the prediction of adolescents' autonomy $(\beta=0.18, p=0.05$; Figure 4). Specifically, parental career interference was associated negatively with adolescents' autonomy when lack of parental career engagement was low $(-1$ $S D, \beta=-0.06, p=0.001)$ but not when lack of parental career engagement was high $(+1 S D, \beta=0.04, p=0.02)$.

Overall, two moderated mediating effects emerged (Table 2). Parental career support interacted with parental lack of engagement in relation to adolescents' CDSE via autonomy: $\beta=-0.13,95 \%$ CI $[-0.21,-0.04]$. Specifically, the indirect effect for parental career support - autonomy - CDSE was larger when parental lack of engagement was low (i.e., parents displayed high levels of career engagement) $(-1 S D, \beta=0.20,95 \% \mathrm{CI}$ $[0.13,0.28])$ than that when parental lack of engagement was high (i.e., parents displayed low levels of career engagement) $(+1 S D, \beta=0.12,95 \%$ CI $[0.08,0.16])$. Parental career interference also interacted with parental lack of engagement in relation to adolescents' CDSE via autonomy: $\beta=0.11,95 \% \mathrm{CI}$ $[0.03,0.22]$. Specifically, the indirect effect for parental career interference - autonomy - CDSE was negative when parental lack of engagement was low $(-1 S D, \beta=-0.07,95 \%$ CI $[-0.10$, $-0.02])$ than when parental lack of engagement was high $(+1 S D$, $\beta=0.04,95 \%$ CI $[0.00,0.07])$.

\section{DISCUSSION}

Based on data from a large sample of Chinese adolescents, this study is among the initial efforts in examining the understudied unique and interactive associations between careerspecific parenting practices and adolescents' CDSE as well as the mediating roles of autonomy in explaining such associations. Identifying antecedents of adolescents' CDSE is critical given that adolescence is an important developmental stage when they seek to learn about personal interests, values, and capabilities, ponder over the potential occupations that may suit their personal characteristics, develop stable identity, and prepare themselves for future career (Lee et al., 2016; Pellerone et al., 2017a).

\section{The Direct Association Between Career-Specific Parenting Practices and on Adolescents' CDSE}

Going beyond the general parenting behaviors and the sole focus on parental career support, this study extended the current research by revealing that adolescents who perceived higher career support from parents reported higher CDSE whereas adolescents perceived interference 


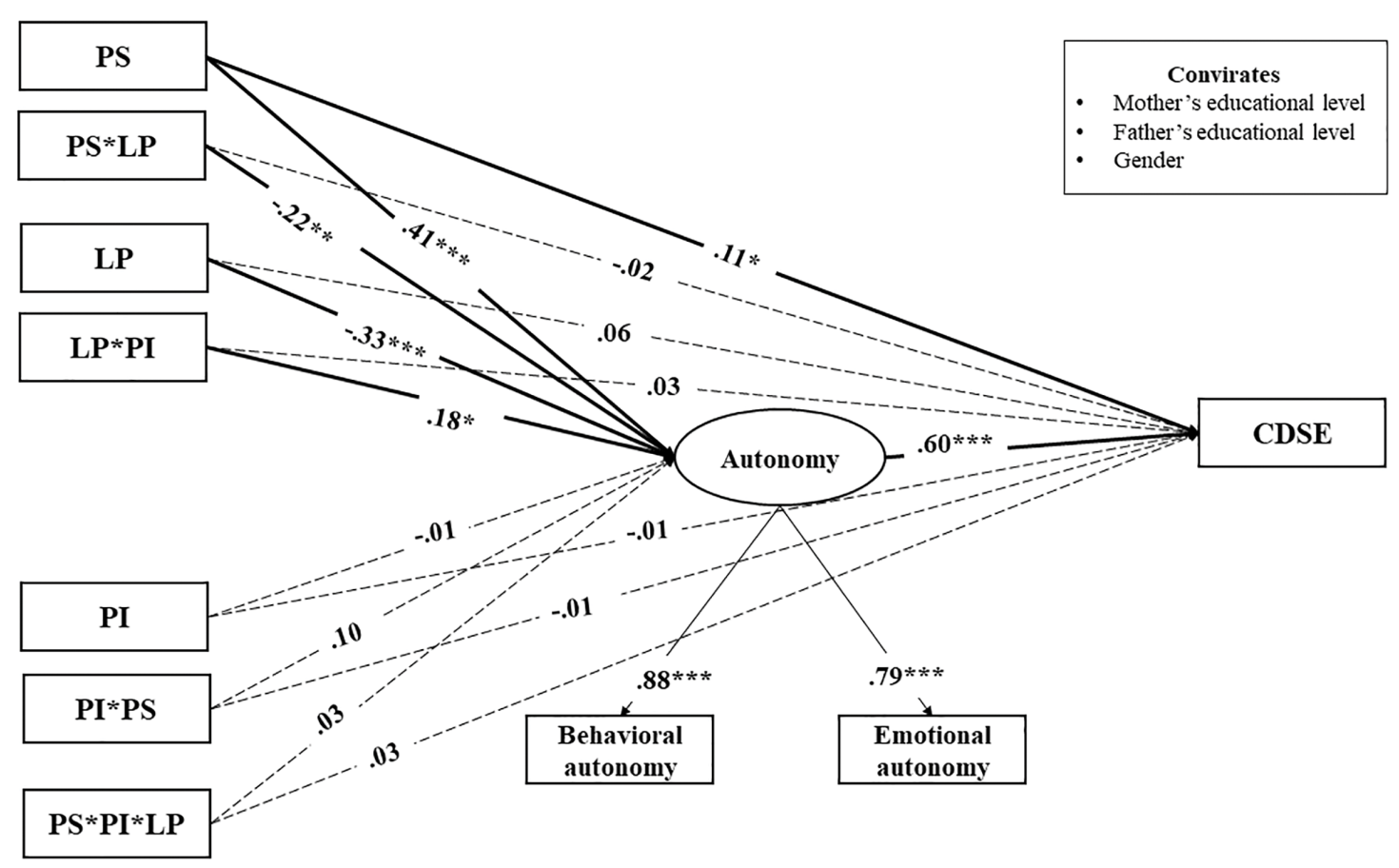

FIGURE 2 | Associations among career-related parenting practices, autonomy, and CDSE. PS, parental career support; PI, parental career interference; LP, lack of parental career engagement; CDSE, career decision-making self-efficacy. To simplify presentation, the correlations between independent variables, and the correlation lines and predicting pathways involving covariates are not shown in the figure. Values are standardized coefficients. Solid lines indicate relations that were significant at $p<0.05$. Parameter estimates for pathways that were not statistically significant at $p<0.05$ (two-tailed) are depicted in dash lines in the figure. ${ }^{*} p<0.05,{ }^{* *} p<0.01,{ }^{* * *} p<0.001$ (two-tailed).

TABLE 1 | Descriptive statistics and correlations $(N=641)$.

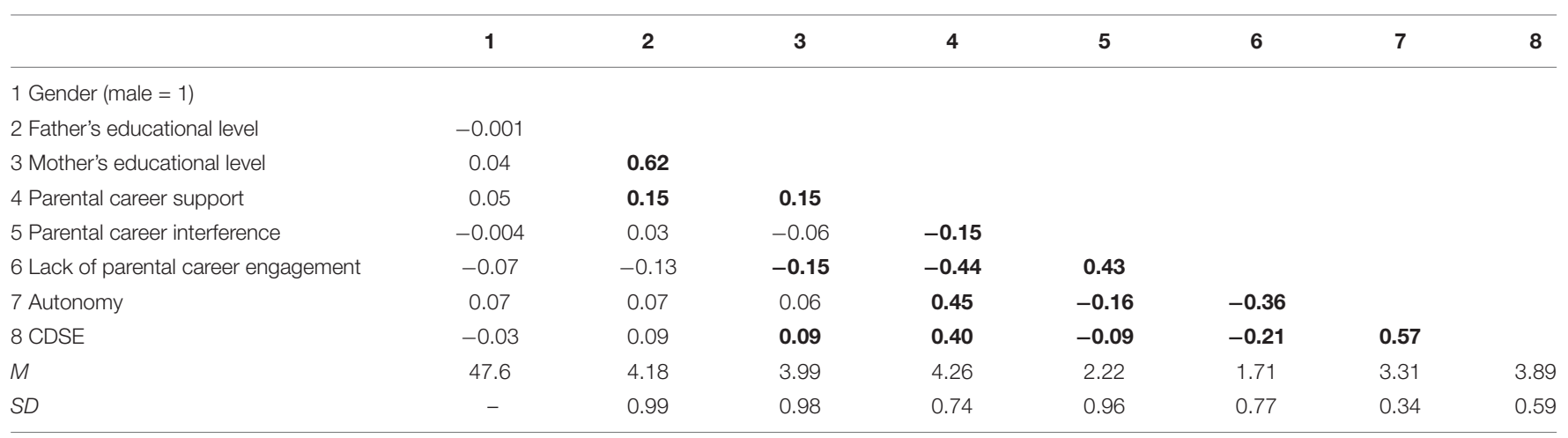

Bold correlations are significant at $p<0.01$. The mean for child sex reflect the percentage of male students. CDSE, career decision-making self-efficacy.

and lack of engagement from parents were not related directly with adolescents' CDSE. The identified, unique association between parental career support and adolescents' CDSE is consistent with the SCCT perspective and joints an emerging body of research highlighting the important role of parents' career support in Chinese adolescents' career development (Lent et al., 1994; Tracey et al., 2006; Keller and Whiston, 2008; Garcia et al., 2012; Zhang et al., 2015). On one hand, parents' career instrumental support in the forms of encouragement, instrumental assistance, and modeling desired behaviors may provide necessary resources to enable career exploration and thus may lead to enhanced confidence and motivation to pursue their career goals (Kanten et al., 2016).

On the other hand, parents' various forms of support also may create an atmosphere that encourages adolescents' active exploration of their selves and environment and also set a stable basis for them to cope with career challenges and to conceive their future (Marcionetti and Rossier, 2017). Taken together, both parents' instrumental and emotional support represent parents' active involvement in adolescents' career development and ultimately may promote adolescents' CDSE. Future research is needed to differentiate between parents' instrumental and emotional 


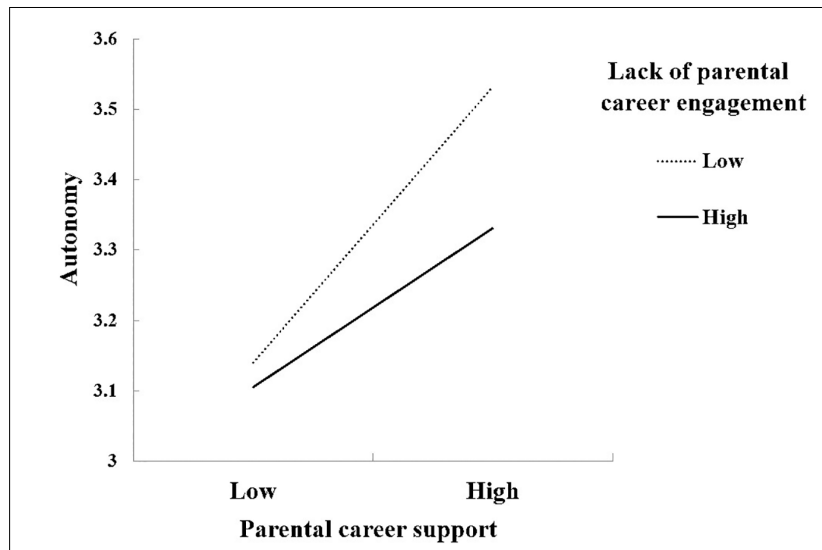

FIGURE 3 | Parental career support interacted with lack of parental career engagement in the prediction of adolescents' autonomy.

support in relation to adolescents CDSE, which holds critical implications for the development of targeted intervention programs.

\section{The Interactive Effects of \\ Career-Specific Parenting Practices on Adolescents' CDSE Through Autonomy}

This study further advances the literature by examining the linking mechanism that underlies associations between careerspecific parenting practices and adolescents' CDSE. Although

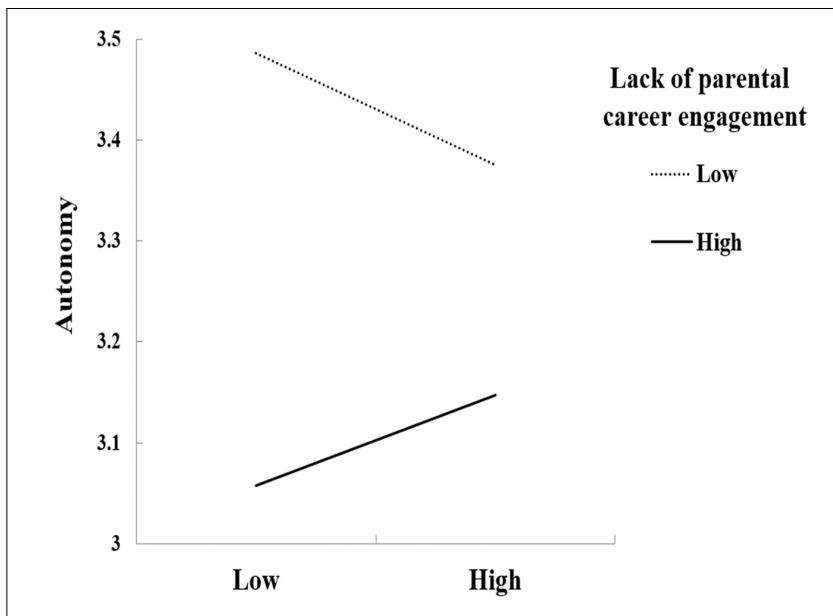

Parental career interference

FIGURE 4 | Parental career interference interacted with lack of parental career engagement in the prediction of adolescents' autonomy.

a self-determination perspective highlights the critical role of autonomy in fostering individuals' development, to our knowledge, this study is one of the first efforts in revealing that autonomy served as the linking mechanism that explained the direct and interactive effects of career-specific parenting practices on adolescents' CDSE.

Specifically, the lack of parental career engagement conditioned the association between parental career support and

TABLE 2 | Conditional indirect effects of different career-specific parental practices on CDSE through autonomy, at varying levels of lack of parent career engagement.

\begin{tabular}{lccc}
\hline Variables & $\beta$ & SE & $\mathbf{9 5 \%} \mathbf{C l}$ \\
\hline$P S$ & $\mathbf{0 . 2 4}$ & $\mathbf{0 . 0 4}$ & $\mathbf{0 . 1 6 , 0 . 3 2}$ \\
PI & -0.004 & 0.04 & $-0.08,0.06$ \\
LP & -0.02 & $\mathbf{0 . 0 5}$ & $-0.34,-0.12$ \\
PS $\times$ PI & 0.06 & 0.05 & $-0.03,0.17$ \\
PS $\times$ LP & $-\mathbf{0 . 1 3}$ & $\mathbf{0 . 0 4}$ & $-\mathbf{0 . 2 1 ,}-\mathbf{0 . 0 4}$ \\
PI $\times$ LP & $\mathbf{0 . 1 1}$ & $\mathbf{0 . 0 5}$ & $\mathbf{0 . 0 3 , 0 . 2 2}$ \\
PS $\times$ PI $\times$ LP & 0.02 & 0.06 & $-0.11,0.12$ \\
\hline
\end{tabular}

\begin{tabular}{lccc}
\hline \multicolumn{4}{c}{ Conditional indirect effects of PS on CDSE at specific values of LP } \\
\hline Value of LP & Indirect effect & SE & $\mathbf{9 5 \%}$ Cl \\
\hline$-1 S D(-0.71)$ & $\mathbf{0 . 2 0}$ & $\mathbf{0 . 0 4}, \mathbf{0 . 2 8}$ \\
$M(0.03)$ & 0.16 & 0.02 & $0.12,0.21$ \\
$+1 S D(0.77)$ & $\mathbf{0 . 1 2}$ & $\mathbf{0 . 0 2}$ & $\mathbf{0 . 0 8 , 0 . 1 6}$ \\
\hline & Conditional indirect effect of PI on CDSE at specific values of LP & SE \\
\hline Value of LP & Indirect effect & $\mathbf{0 . 0 2}$ & $\mathbf{9 5 \%}$ Cl \\
\hline$-1 S D(-0.71)$ & -0.07 & 0.02 & $-0.10,-0.02$ \\
$M(0.03)$ & -0.01 & $\mathbf{0 . 0 2}$ & $-0.04,0.02$ \\
$+1 S D(0.77)$ & $\mathbf{0 . 0 4}$ & $\mathbf{0 . 0 0 , 0 . 0 7}$
\end{tabular}

All parameter estimates and significance tests are based on 2,000 bootstrapped samples. SE, standard error. Significant effects are determined by both $95 \%$ CI that does not include zero and ps $<0.05$, which are in bold typeface for emphasis. PS, parental career support; PI, parental career interference; LP, lack of parental career engagement; CDSE, career decision-making self-efficacy. 
adolescents' CDSE as well as the negative association between parental career interference and adolescents' autonomy. The results indicated that whether parents' engagement in their children's career development (i.e., lower levels of lack of parental career engagement) foster either higher or lower CDSE via autonomy is contingent upon whether parents provide actual guidance and/or warmth (i.e., higher levels of parental career support) or over-control their children's career direction or actions (i.e., higher levels of parental career interference).

These interactive effects are consistent with results of prior studies (Dietrich and Kracke, 2009; Guan et al., 2015). Specifically, the conveyance of competence and confidence in career exploration and making career decisions (i.e., CDSE) based on parents' career guidance and warm support tends to be strengthened by parents' active engagement (Lent et al., 1994, 2017). These findings also were consistent with the selfdetermination perspective such that parents' high levels of career support (e.g., warmth, encouragement and provision of necessary career planning or exploration resources) coupled with parents' active engagement may provide opportunities for adolescents to explore valuable information and experiences and thus to gain insights for future career via enhanced sense of autonomy (Deci and Ryan, 1985; Guay et al., 2003; Dietrich and Salmela-Aro, 2013). In contrast, when parents approach their adolescents' career development with controlling behaviors (i.e., parental career interference), or without sufficient support may perceive a high level of difficulty in coping with and overcoming the challenges in their career development due to compromised intrinsic motivation associated with autonomy (Amarnani et al., 2018). These findings contributes to the literature by revealing 'how' the interplay of different careerspecific parenting practices relate to adolescents' CDSE (Deci and Ryan, 1985; Lent et al., 1994).

Furthermore, the amplifying effect of engagement in facilitating adolescents' CDSE via providing career support also is consistent with a self-verification theory such that the positive social feedback engendered by parental career support is likely to be facilitated by heightened parental engagement (Swann et al., 1992). In contrast, in the context of parents' ignorance or incapability to provide guidance for adolescents' career development, adolescents are prone to deviate from career exploration and actions and thus may lead to adolescents' compromised autonomy and ultimately undermined confidence in making career decisions (Amarnani et al., 2018). However, parents' active career engagement coupled with intrusive and controlling career involvement (i.e., parents' imposing their own thoughts on their children's career directions and explorations) tend to undermine adolescents' autonomy given parental career interference imply to adolescents that they are not able to effectively engage in career exploration, establish career direction and goal, and/or make adaptive career decisions (Dietrich and Kracke, 2009; Guan et al., 2015).

\section{Implications for Practice}

As there is not yet national, official career guidance programs for high school students in China, Chinese parents' careerspecific parenting behaviors may play a significant role in facilitating Chinese adolescents' career development. The examination of the relationships between different career-specific parenting behaviors and Chinese high school students' CDSE may have important implications for Chinese high school's career guidance practice. First, parenting-based interventions to promote adolescents' CDSE is justified in the Chinese context. Specifically, school psychologists may find it useful to tailor interventions to increase students' CDSE through targeting their parents' career-specific parenting behaviors and enhancing their autonomy. Second, although more and more Chinese high schools begin to develop career guidance programs in recent years ( $\mathrm{Hu}$ et al., 2015), there are only a limited number of counselors in Chinese high schools. As such, it is important to identify students who need more intensive career counseling interventions ( $\mathrm{Hu}$ et al., 2015). The present study provides potential directions to identify potential clients, like those students who perceived their parents displaying high levels of career-related engagement and over-controlling parenting practices. Moreover, the present study highlights the importance of strengthening schoolfamily partnerships, which may provide students with parental career involvement and autonomous support for their adolescent kids, which may ultimately facilitate students' CDSE (Watkinson and Hersi, 2014).

\section{Limitations and Future Directions}

The present study should be considered in light of its limitations. First, as adolescents reported career-specific parenting practices and CDSE on their own, some of the identified associations may be inflated. Future studies are warranted to employ multi-informant and multimethod designs to minimize shared informant and method bias. Second, given the widespread grandparents' heavy involvement in Chinese adolescents' daily lives and potential different parenting practices executed by grandparents from parents (Chen et al., 2011), it is not clear how career-specific parenting practices and adolescents' CDSE may vary between adolescents raised mainly by grandparents and those by parents. Finally, given the cross-sectional nature of the data used, the presents study cannot address the temporal dynamics of the examined associations. Future research with longitudinal designs is warranted.

\section{ETHICS STATEMENT}

This study was carried out in accordance with the recommendations of Ethics Review Committee at the School of Psychology, Beijing Normal University with written informed consent from all the participants. All the adolescents and their parents gave written informed consent in accordance with the Declaration of Helsinki. The protocol was approved by the Ethics Review Committee at the School of Psychology, BNU. 


\section{AUTHOR CONTRIBUTIONS}

YZ, NZ, HC, YL, QW, and XF designed the study and drafted the manuscript. YZ, RS, PL, QX, and RN performed the research. $\mathrm{YZ}$ and $\mathrm{NZ}$ analyzed the data and revised the manuscript. SY, JL, $\mathrm{LD}$, and RS re-analyzed the data and revised the manuscript. All authors approved the final version of manuscript for submission.

\section{REFERENCES}

Acock, A. C. (2005). Working with missing values. J. Marriage Fam. 67, 1012-1028. doi: 10.1111/j.1741-3737.2005.00191.x

Amarnani, R. K., Garcia, P. R. J. M., Restubog, S. L. D., Bordia, P., and Bordia, S. (2018). Do you think I'm worth It? The self-verifying role of parental engagement in career adaptability and career persistence among STEM students. J. Car. Assess. 26, 77-94. doi: 10.1177/1069072716679925

Anderson, R. A., Worthington, L., Anderson, W. T., and Jennings, G. (1994). The development of an autonomy scale. Contemp. Fam. Ther. 16, 329-345. doi: 10.1007/BF02196884

Bandura, A. (2002). "Social foundations of thought and action," in The Health Psychology Reader, ed. D. F. Marks (London: SAGE Publications Ltd), 94-106. doi: 10.4135/9781446221129.n6

Betz, N. E., Klein, K. L., and Taylor, K. M. (1996). Evaluation of a short form of the career decision-making self-efficacy scale. J. Career Assess. 4, 47-57. doi: 10.1177/106907279600400103

Browne, M. W., and Cudeck, R. (1993). “Alternative ways of assessing model fit," in Testing Structural Equation Models, Eds. K. A. Bollen, and J. S. Long (Newbury Park, CA: SAGE), 136-162.

Byrne, B. M. (2001). Structural equation modeling: perspectives on the present and the future. Int. J. Test. 1, 327-334. doi: 10.1080/15305058.2001. 9669479

Chen, F., Liu, G., and Mair, C. A. (2011). Intergenerational ties in context: grandparents caring for grandchildren in china. Soc. Forces 90, 571-594. doi: $10.1093 /$ sf/sor012

Chiesa, R., Massei, F., and Guglielmi, D. (2016). Career decision-making selfefficacy change in italian high school students. J. Counsel. Dev. 94, 210-224. doi: $10.1002 /$ jcad. 12077

Chirkov, V. I. (2009). A cross-cultural analysis of autonomy in education: a selfdetermination theory perspective. Theor. Res. Educ. 7, 253-262. doi: 10.1177/ 1477878509104330

Choi, B. Y., Park, H., Yang, E., Lee, S. K., Lee, Y., and Lee, S. M. (2012) Understanding career decision self-efficacy: a meta-analytic approach. J. Career Dev. 39, 443-460. doi: 10.1177/0894845311398042

Cordeiro, P. M. G., Paixão, M. P., Lens, W., Lacante, M., and Luyckx, K. (2015). Cognitive-motivational antecedents of career decision-making processes in portuguese high school students: a longitudinal study. J. Vocat. Behav. 90, 145-153. doi: 10.1016/j.jvb.2015.08.005

Costa, S., Cuzzocrea, F., Gugliandolo, M. C., and Larcan, R. (2016). Associations between parental psychological control and autonomy support, and psychological outcomes in adolescents: the mediating role of need satisfaction and need frustration. Child Indic. Res. 9, 1059-1076. doi: 10.1007/s12187-015-9353-z

Deci, E. L., and Ryan, R. M. (1985). Intrinsic Motivation and Self-Determination in Human Behavior. Heidelberg: Springer. doi: 10.1007/978-1-4899-2271-7

Deci, E. L., and Ryan, R. M. (2000). The "What" and "Why" of goal pursuits: human needs and the self-determination of behavior. Psychol. Inq. 11, 227-268. doi: 10.1207/S15327965PLI1104-01

Dietrich, J., and Kracke, B. (2009). Career-specific parental behaviors in adolescents' development. J. Vocat. Behav. 75, 109-119. doi: 10.1016/j.jvb.2009. 03.005

Dietrich, J., and Salmela-Aro, K. (2013). Parental involvement and adolescents' career goal pursuit during the post-school transition. J. Adolesc. 36, 121-128. doi: 10.1016/j.adolescence.2012.10.009

Doren, B., and Kang, H. J. (2016). Autonomy, self-realization, and self-advocacy and the school- and career-related adjustment of adolescent girls with

\section{FUNDING}

This study was supported by the Key Research Institute of Humanities and Social Sciences of the Ministry of Education of the People's Republic of China (16JJD880009) and the Fundamental Research Funds for the Central Universities (310422104).

disabilities. Career Dev. Trans. Excep. Individ. 39, 132-143. doi: 10.1177/ 2165143415574875

Fleisher, B. M. (2014). China's college entrance examination: editorial introduction. China Econ. Rev. 30:599. doi: 10.1016/j.chieco.2014.05.008

Friedman, D., Holmbeck, G. N., Delucia, C., Jandasek, B., and Zebracki, K. (2009). Trajectories of autonomy development across the adolescent transition in children with spina bifida. Rehabil. Psychol. 54, 16-27. doi: 10.1037/a0014279

Garcia, P. R., Restubog, S. L., Bordia, P., Bordia, S., and Roxas, R. E. (2015). Career optimism: the roles of contextual support and career decision-making self-efficacy. J. Vocat. Behav. 88, 10-18. doi: 10.1016/j.jvb.2015.02.004

Garcia, P. R. J. M., Restubog, S. L. D., Toledano, L. S., Tolentino, L. R., and Rafferty, A. E. (2012). Differential moderating effects of student- and parentrated support in the relationship between learning goal orientation and career decision-making self-efficacy. J. Career Assess. 20, 22-33. doi: 10.1177/ 1069072711417162

Gianakos, I. (2001). Predictors of career decision-making self-efficacy. J. Career Assess. 9, 101-114. doi: 10.1177/106907270100900201

Grolnick, W. S., Ryan, R. M., and Deci, E. L. (1991). Inner resources for school achievement: motivational mediators of children's perceptions of their parents. J. Educ. Psychol. 83, 508-517. doi: 10.1037//0022-0663.83.4.508

Guan, P., Capezio, A., Restubog, S. L. D., Read, S., Lajom, J. A. L., and Li, M. (2016). The role of traditionality in the relationships among parental support, career decision-making self-efficacy and career adaptability. J. Vocat. Behav. 94, 114-123. doi: 10.1016/j.jvb.2016.02.018

Guan, Y., Wang, F., Liu, H., Ji, Y., Jia, X., Fang, Z., et al. (2015). Career-specific parental behaviors, career exploration and career adaptability: a three-wave investigation among chinese undergraduates. J. Vocat. Behav. 86, 95-103. doi: 10.1016/j.jvb.2014.10.007

Guay, F., Senécal, C., Gauthier, L., and Fernet, C. (2003). Predicting career indecision: a self-determination theory perspective. J. Counsel. Psychol. 50, 165-177. doi: 10.1037/0022-0167.50.2.165

Gushue, G. V. (2006). The relationship of ethnic identity, career decision-making self-efficacy and outcome expectations among Latino/a high school students. J. Vocat. Behav. 68, 85-95. doi: 10.1016/j.jvb.2005.03.002

Gushue, G. V., Clarke, C. P., Pantzer, K. M., and Scanlan, K. R. L. (2006). Selfefficacy, perceptions of barriers, vocational identity, and the career exploration behavior of Latino/a high school students. Career Dev. Quar. 54, 307-317. doi: 10.1002/j.2161-0045.2006.tb00196.x

Gushue, G. V., and Whitson, M. L. (2006). The relationship among support, ethnic identity, career decision self-efficacy, and outcome expectations in african american high school students: applying social cognitive career theory. J. Career Dev. 33, 112-124. doi: 10.1177/0894845306293416

Hampton, N. Z. (2006). A psychometric evaluation of the career decision selfefficacy scale-short form in chinese high school students. J. Career Dev. 33, 142-155. doi: 10.1177/0894845306293540

Hayes, A. F. (2009). Beyond baron and kenny: statistical mediation analysis in the new millennium. Commun. Monograp. 76, 408-420. doi: 10.1080/ 03637750903310360

Hmel, B. A., and Pincus, A. L. (2002). The meaning of autonomy: on and beyond the interpersonal circumplex. J. pers. 70, 277-310. doi: 10.1111/1467-6494. 05006

Hsieh, H. H., and Huang, J. T. (2014). The effects of socioeconomic status and proactive personality on career decision self-efficacy. Career Dev. Quar. 62, 29-43. doi: 10.1002/j.2161-0045.2014.00068.x

Hu, L., and Bentler, P. M. (1999). Cutoff criteria for fit indexes in covariance structure analysis: conventional criteria versus new alternatives. Struct. Equ. Modeling 6, 1-55. doi: 10.1080/10705519909540118 
Hu, W., Fang, X., Chen, H., Deng, L., and Lin, X. (2015). The relationship between three-domain competences and internalizing and externalizing problems in chinese high school students. Child Indic. Res. 8, 943-959. doi: 10.1007/s12187014-9290-2

Kanten, S., Kanten, P., and Yeşiltaş, M. (2016). The role of career self-efficacy on the effect of parental career behaviors on career exploration: a study on school of turism and hotel management's students. Eur. J. Multidiscipl. Stud. Articl. 3, 144-155. doi: 10.26417/ejms.v3i1.p143-154

Keller, B. K., and Whiston, S. C. (2008). The role of parental influences on young adolescents' career development. J. Career Assess. 16, 198-217. doi: 10.1177/ 1069072707313206

Lee, B., Porfeli, E. J., and Hirschi, A. (2016). Between-and within-person level motivational precursors associated with career exploration. J. Vocat. Behav. 92, 125-134. doi: 10.1016/j.jvb.2015.11.009

Lent, R. W., Brown, S. D., and Hackett, G. (1994). Toward a unifying social cognitive theory of career and academic interest, choice, and performance. J. Vocat. Behav. 45, 79-122. doi: 10.1006/jvbe.1994.1027

Lent, R. W., Ireland, G. W., Penn, L. T., Morris, T. R., and Sappington, R. (2017). Sources of self-efficacy and outcome expectations for career exploration and decision-making: a test of the social cognitive model of career self-management. J. Vocat. Behav. 99, 107-117. doi: 10.1016/j.jvb.2017.01.002

Lim, V. K. G., and Loo, G. L. (2003). Effects of parental job insecurity and parenting behaviors on youth's self-efficacy and work attitudes. J. Vocat. Behav. 63, 86-98. doi: 10.1016/S0001-8791(02)00020-9

Luzzo, D. A. (1993). Value of career-decision-making self-efficacy in predicting career-decision-making attitudes and skills. J. Counsel. Psychol. 40, 194-199. doi: 10.1037/0022-0167.40.2.194

Marcionetti, J., and Rossier, J. (2017). The mediating impact of parental support on the relationship between personality and career indecision in adolescents. J. Career Assess. 25, 601-615. doi: 10.1177/1069072716 652890

Miles, J., and Naidoo, A. V. (2017). The impact of a career intervention programme on south african grade 11 learners' career decision-making self-efficacy. South Afr. J. Psychol. 47, 209-221. doi: 10.1177/008124636654804

Mortimer, J. T., Zimmer-Gembeck, M. J., Holmes, M., and Shanahan, M. J. (2002). The process of occupational decision making: patterns during the transition to adulthood. J. Vocat. Behav. 61, 439-465. doi: 10.1006/jvbe. 2002.1885

Pan, Y., Gauvain, M., and Schwartz, S. J. (2013). Do parents' collectivistic tendency and attitudes toward filial piety facilitate autonomous motivation among young chinese adolescents? Motivat. Emot. 37, 701-711. doi: 10.1007/s11031-0129337-y

Patel, S. G., Salahuddin, N. M., and O’Brien, K. M. (2008). Career decision-making self-efficacy of vietnamese adolescents: the role of acculturation, social support, socioeconomic status, and racism. J. Career Dev. 34, 218-240. doi: 10.1177/ 0894845307308488

Pedro, M. G. C., Maria, P. P., Willy, L., Marlies, L., and Koen, L. (2016). Parenting styles, identity development, and adjustment in career transitions: the mediating role of psychological needs. J. Career Dev. 45, 83-97. doi: 10.1177/ 0894845316672742

Pellerone, M., Ramaci, T., López, M. H., and Craparo, G. (2017a). The role of identity development and decision making process on adult attachment: a cross-national study in sicilian and andalusian adolescents. Clin. Neuropsychiatr. 14, 141-150.
Pellerone, M., Tomasello, G., and Migliorisi, S. (2017b). Relationship between parenting, alexithymia and adult attachment styles: a cross-sectional study on a group of adolescents and young adults. Clin. Neuropsychiatr. 14, 125-134.

Pesch, K. M., Larson, L. M., and Surapaneni, S. (2016). Parental autonomy support and career well-being: mediating effects of perceived academic competence and volitional autonomy. J. Career Assess. 24, 497-512. doi: 10. $1177 / 1069072715599392$

Podsakoff, P. M., and Organ, D. W. (1986). Self-reports in organizational research: problems and prospects. J. Manag. 12, 531-544. doi: 10.1177/ 014920638601200408

Preacher, K. J., Rucker, D. D., and Hayes, A. F. (2007). Addressing moderated mediation hypotheses: theory, methods, and prescriptions. Multivariate Behav. Res. 42, 185-227. doi: 10.1080/002731707013 41316

Sovet, L., and Metz, A. J. (2014). Parenting styles and career decision-making among french and korean adolescents. J. Vocat. Behav. 84, 345-355. doi: 10. 1016/j.jvb.2014.02.002

Swann, W. B. Jr., Wenzlaff, R. M., Krull, D. S., and Pelham, B. W. (1992). Allure of negative feedback: self-verification strivings among depressed persons. J. Abnorm. Psychol. 101, 293-306.doi: 10.1037/0021-843X.101. 2.293

Taylor, K. M., and Betz, N. E. (1983). Applications of self-efficacy theory to the understanding and treatment of career indecision. J. Vocat. Behav. 22, 63-81. doi: 10.1016/0001-8791(83)90006-4

Tracey, T. J. G., Lent, R. W., Brown, S. D., Soresi, S., and Nota, L. (2006). Adherence to RIASEC structure in relation to career exploration and parenting style: longitudinal and idiothetic considerations. J. Vocat. Behav. 69, 248-261. doi: 10.1016/j.jvb.2006.02.001

Watkinson, J. S., and Hersi, A. A. (2014). School counselors supporting african immigrant students' career development: a case study. Career Dev. Quar. 62, 44-55. doi: 10.1002/j.2161-0045.2014.00069.x

Zhang, J., Yuen, M., and Chen, G. (2015). Career-related parental support for vocational school students in china. Int. J. Adv. Counsel. 37, 346-354. doi: 10.1007/s10447-015-9248-1

Zhao, X., Lim, V. K. G., and Teo, T. S. H. (2012). The long arm of job insecurity: its impact on career-specific parenting behaviors and youths' career self-efficacy. J. Vocat. Behav. 80, 619-628. doi: 10.1016/j.jvb.2012. 01.018

Zhou, M. M., Ma, W. J., and Deci, E. L. (2009). The importance of autonomy for rural chinese children's motivation for learning. Learn. Individ. Diff. 19, 492-498. doi: 10.1016/j.lindif.2009. 05.003

Conflict of Interest Statement: The authors declare that the research was conducted in the absence of any commercial or financial relationships that could be construed as a potential conflict of interest.

Copyright (c) 2019 Zhang, Zhou, Cao, Liang, Yu, Li, Deng, Sun, Wu, Li, Xiong, Nie and Fang. This is an open-access article distributed under the terms of the Creative Commons Attribution License (CC BY). The use, distribution or reproduction in other forums is permitted, provided the original author(s) and the copyright owner(s) are credited and that the original publication in this journal is cited, in accordance with accepted academic practice. No use, distribution or reproduction is permitted which does not comply with these terms. 